\title{
The Association of Anterior Teeth Appearance and Psychosocial Level Using Spearman Correlation for Teenagers
}

\author{
S Susi ${ }^{1}$, R Semiarty ${ }^{2}, \mathrm{H}$ Viyanti ${ }^{3}$, M Murniwati $^{4}$, M Minarni $^{5}$ \\ Dentistry Faculty, Andalas University, Indonesia ${ }^{1,3,4}$ \\ Medicine Faculty, Andalas University, Indonesia ${ }^{2}$ \\ Health Polytechnic of Health Ministry Padang, Indonesia ${ }^{5}$
}

\{susi@dent.unand.co.id $\left.{ }^{1}\right\}$

\begin{abstract}
Dentofacial aesthetics disorders such as malocclusions have a negative impact on psychosocial conditions that will interfere with psychological wellbeing especially in adolescence. Some aspects of facial appearance and dental aesthetics are important for their self-esteem. Soh, et al stated that malocclusion, especially in anterior teeth, leads to negative self-concept. This study aims to investigate the correlation between anterior teeth appearance on teenagers' psychosocial. This is a cross-sectional study located in SMA 10 Padang. In this study 89 students aged 14-18 years were selected. The anterior teeth appearance was assessed using a standard Aesthetic Component photograph of the Aesthetic Component of Index of Orthodontic Treatment Need grade 1 (IOTN). Psychosocial conditions will be observed by the self-rated Psychosocial Impact of Dental Aesthetics Questionnaire (PIDAQ) questionnaires. Data were analyzed using the Spearman and Mann Whitney test. There is a 31.5\% sample with the best aesthetic score and $66 \%$ sample did not need orthodontic treatment. The effect of anterior tooth appearance on psychosocial ( $p<0.001)$, on self-esteem $(\mathrm{p}<0.001)$, on social impact $(\mathrm{p}<0.05)$, on psychological impact $(\mathrm{p}<0.005)$, and on esthetic impact $(\mathrm{p}<0.05)$.There is a significant relationship between the anterior teeth appearance based on Aesthetic Component from IOTN and the teenager's psychosocial.
\end{abstract}

Keywords: anterior teeth appearance, teenagers psychosocial, PIDAQ and AC IOTN

\section{Introduction}

Dentofacial aesthetics disorders such as malocclusion are one of the world's health problems [1]. Studies epidemiology in the United States reported $89 \%$ of adolescents experienced malocclusion from mild to severe [2]. Malocclusions not only disrupt oral function and appearance but also disturb the psychological, social and economic aspects [3].

Malocclusion is the anterior teeth can be seen in speech and smile so we could easily aware of its existence [4]. They who have malocclusion often receive an unpleasant response from 
others such as mockery or nicknames. Shaw stated that who suffered malocclusion are shy and tend to have low popularity. The psychological impact of malocclusion makes them feel inferior, difficult to adapt, and emotionally disturbed [2]. Malocclusion affects development, especially in adolescence, which looking for their identity [5]. Shaw, et al stated that if a person is not satisfied with the appearance of teeth since childhood, it will most likely be felt throughout his life [6].

Index of Orthodontic Treatment Need (IOTN) is one of the measuring tools that used to describe the level of need for orthodontic treatment in a population. IOTN was introduced by Brook and Shaw in 1989. IOTN consists of Dental Health Component (DHC) and Aesthetic component (AC). Aesthetic component is used to assess the impact of malocclusion on the patient's psychosocial condition [2], [7]. Psychosocial Impact of Dental Aesthetics Questionnaire (PIDAQ) is an instrument or psychometric measuring instrument that can measure the psychosocial impact of dental aesthetics and quality of life from orthodontic aspects. The PIDAQ questionnaire has been tested for its validity and reliability and has been used in a wide variety of research samples [8]. This study aims to investigate the effect of anterior teeth on adolescent's psychosocial.

\section{Method}

This is a Cross-sectional study located in SMA 10 Padang, data collection was done in January-February 2014. The sample of 89 people with the age range of 14-18 years were selected by simple random sampling from 789 people. Data was taken by 4 dentistry students who have been calibrated before. The anterior teeth appearance was assessed using a standard photo of Aesthetic Component of the Index of Orthodontic Treatment Need (IOTN). The psychosocial state was assessed by a self-rated Psychosocial Impact of the Dental Aesthetics Questionnaire (PIDAQ).

PIDAQ questionnaire to assess the psychosocial condition using a numerical scale. The questionnaire aspect consists of self-confidence, social impact, psychological impact, and aesthetic impact. Questions about social impact, psychological impact, and aesthetic impact are assessed with the terms 0 , disagree, $1=$ slightly agree, $2=$ slightly agree, $3=$ agree, and $4=$ strongly agree. Questions about the self-confidence aspect with a value of $4=$ agree, value $3=$ slightly agree, value $2=$ somewhat agree, value $1=$ agree, and value $0=$ strongly agree. Psychosocial condition measurement results were obtained by adding up the overall score of the questionnaire. The greater the total score, the more negatively affect the psychosocial condition of the respondents.

Observation to compare the appearance of the tooth during centric occlusion with 10 standards of Aesthetic Component photos from IOTN, then chooses the photo closest to the subject's appearance. The anterior tooth appearance of the sample in the centric occlusion position is documented using the camera from the anterior direction. The data were analyzed using the Spearman correlation test and Man Whitney test. Significance was set at, p <0.05 (significance Level 95\%).

\section{Result and Discussion}

The sample consisted of 56 women and 33 men with an average age of 15, 9 years. 


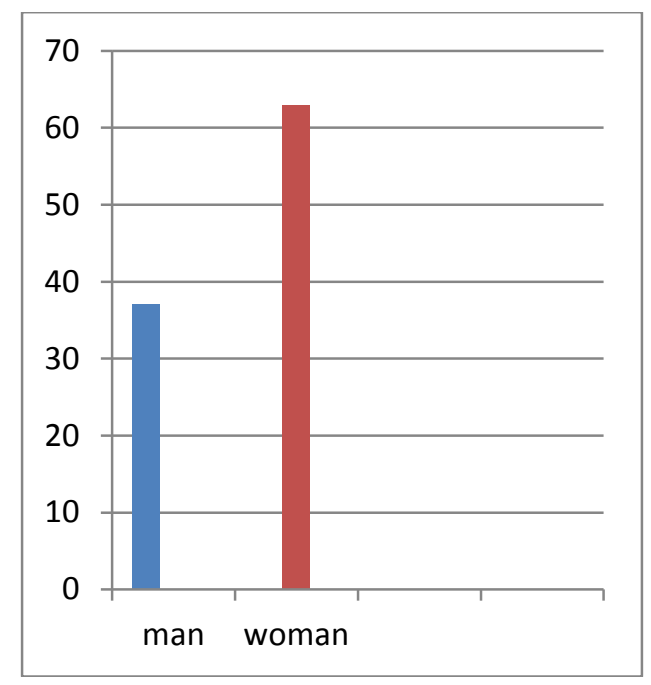

Figure 1: gender

Table 1: Age

\begin{tabular}{lllll}
\hline & mean & median & min & $\max$ \\
\hline age & 15.92 & 16.00 & 14.00 & 18.00 \\
\hline
\end{tabular}

In this study, the average age of the respondent was 15.92 years old, where all the permanent teeth had erupted except the third molars so the possibility of the irregularity of teeth is reduced.

\begin{tabular}{lccc}
\multicolumn{4}{c}{ Table 2: Aesthetic Component of IOTN and PIDAQ } \\
\hline AC IOTN & $\mathrm{n}$ & $\%$ & $\begin{array}{c}\text { PIDAQ } \\
\text { (Mean) }\end{array}$ \\
\hline Grade 1 & 28 & 31,5 & 24,07 \\
Grade 2 & 12 & 13,5 & 29,17 \\
Grade 3 & 17 & 19,1 & 30,24 \\
Grade 4 & 9 & 10,1 & 27,44 \\
Grade 5 & 1 & 1,1 & 66,00 \\
Grade 6 & 9 & 10,1 & 34,56 \\
Grade 7 & 4 & 4,5 & 43,25 \\
Grade 8 & 8 & 9,0 & 40,38 \\
Grade 9 & 0 & 0 & 0 \\
Grade 10 & 1 & 1,1 & 82,00 \\
\hline
\end{tabular}

Table 2 shows that most samples (31.5\%) in the Aesthetic Component were in grade 1 . The higher the grade on Aesthetic Component, the lower the aesthetic value become. According to Brook and Shaw [9], grade 1 is the highest dental aesthetic based on the Aesthetic Component of IOTN [10]. The results of Klages, et al. [9] most samples of young adults that used the AC IOTN method were in grade 1. The results of Khan and Fida [4] show that adults in Pakistan were also in grade 1 . In this study, it can be concluded that the respondents are in grade 1 according to AC IOTN. Grade 1 AC IOTN does not require orthodontic treatment [7]. 
Grade 1 AC IOTN to 4 does not require orthodontic treatment / light treatment, grade 5-7 requires moderate/borderline care, grade 8-10 is in need of care.

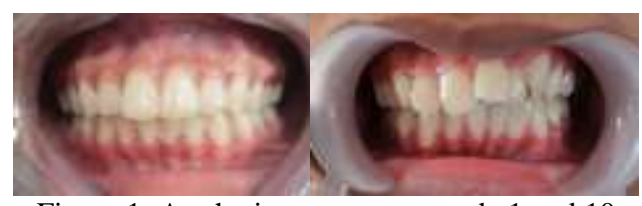

Figure 1: Aesthetic component grade 1 and 10

The result showed that the sample with a higher grade has a greater impact on psychosocial than the respondents with a lower grade. The face is the most frequently considered and become an important physical character in the development of self-image and self-esteem [4].

The face part that greatly affects the physical appearance is the eyes and mouth [11]. The appearance of teeth and mouth affects the person's psychosocial life such as self-image, selfesteem, and social welfare [11].

Good tooth arrangement and a charming smile have an impact on good social life, on the contrary, the irregular teeth arrangement, protrusive teeth have a bad effect on social life. The social response due to dental appearance can affect a person's adaptability [2]. Dental appearance can affect self-esteem and self-concept and quality of life such as social interaction, relationships with others and psychosocial circumstances [4]. Orthodontic treatment is not just a matter of beauty, but also a quality of life. Orthodontic treatment aims to minimize psychosocial problems due to the appearance of teeth and face [2].

Table 3. PIDAQ score

\begin{tabular}{ccccccc}
\hline \multirow{2}{*}{ AI } & \multirow{2}{*}{$\mathrm{n}$} & \multicolumn{5}{c}{ PIDAQ (Mean) } \\
\cline { 3 - 7 } & & $\mathrm{P}$ & $\mathrm{Se}$ & $\mathrm{Psi}$ & $\mathrm{Pi}$ & $\mathrm{Ai}$ \\
\hline $\mathrm{G} 1$ & 28 & 24,07 & 9,14 & 6,79 & 6,39 & 1,75 \\
\hline G 2 & 12 & 29,17 & 12,83 & 6,17 & 8,00 & 2,17 \\
\hline G 3 & 17 & 30,24 & 12,82 & 8,35 & 7,76 & 1,29 \\
\hline G 4 & 9 & 27,44 & 12,78 & 6,56 & 6,44 & 1,67 \\
\hline G 5 & 1 & 66,00 & 21,00 & 21,00 & 15,00 & 9,00 \\
\hline G 6 & 9 & 34,56 & 15,44 & 8,33 & 8,44 & 2,33 \\
\hline G 7 & 4 & 43,25 & 17,25 & 12,25 & 10,25 & 3,50 \\
\hline G 8 & 8 & 40,38 & 16,88 & 9,88 & 10,25 & 3,38 \\
\hline G 9 & 0 & 0 & 0 & 0 & 0 & 0 \\
\hline G 10 & 1 & 82,00 & 24,00 & 28,00 & 21,00 & 9,00 \\
\hline
\end{tabular}

Note:

AI: AC IOTN, G: Grade, P: PIDAQ

Se: Self-esteem, Psi: Psychosocial impact

Ps: Psychology impact, Ai: Aesthetic impact

Table 3 shows the highest average PIDAQ total in the sample with grade 10 AC IOTN and the lowest in grade 1 AC IOTN. Seen from the confidence found the highest average score on grade $10 \mathrm{AC}$ IOTN and the lowest in grade $1 \mathrm{AC}$ IOTN. Viewed from the social impact aspect 
obtained the highest average score on grade $10 \mathrm{AC}$ IOTN and the lowest in grade $2 \mathrm{AC}$ IOTN. In the psychological impact aspect, the highest average score was found on grade 10 AC IOTN and the lowest was in grade 1. Judging from the aesthetic impact aspect, the highest scores were on grade 5 and grade 10 and the lowest was in grade 3 of AC IOTN. The higher the score, the more negatively affect the psychosocial state.

\begin{tabular}{lccc}
\multicolumn{4}{l}{ Table 4: Asthetic Component effect on Psychosocial } \\
\hline Variabel & $\mathrm{N}$ & $\begin{array}{l}\text { Correlation } \\
\text { Coefficient }\end{array}$ & $\mathrm{P}$ \\
\hline $\begin{array}{l}\text { PIDAQ } \\
\text { score }\end{array}$ & 89 & 0,391 & $0,000^{*}$ \\
\hline & $* \mathrm{p}<0,01$ &
\end{tabular}

Based on table 3., the correlation coefficient shows a positive value where the higher the grade of AC IOTN, the higher the PIDAQtotal score. According to the results of statistical tests, can be concluded that the appearance of anterior teeth based on Aesthetic Component from IOTN has a significant influence on psychosocial.

The results of this study are consistent with the research of Carlos Bellot et al [12] on adolescents in Spain, where there is a significant influence between the grade of Aesthetic Component of IOTN and PIDAQ scores of adolescents. Similar results were also found in Paula et al [13] that studied the adolescents in Brazil where there was a significant relationship between malocclusions and psychosocial. Stejepan et all, research in Croatia (2014) was found to have a significant association between PIDAQ scores with psychosocial adolescents.

Arsie's research (2012) in early adolescence in Jakarta found no significant differences between anterior teeth malocclusion characteristics to psychosocial. Arsie's research was conducted at SMP 51 and SMP 159 East Jakarta. The difference may be due to the school environment and social environment that do not prioritize the appearance to socialize. In addition, the socio-economic background of different respondents also cause the difference in result.

\begin{tabular}{cccc}
\multicolumn{4}{c}{ Table 5. Aesthetic Component effect on PIDAQ } \\
\hline Variabel & $\mathrm{N}$ & $\begin{array}{c}\text { Correlation } \\
\text { coefficient }\end{array}$ & $\mathrm{P}$ \\
\hline Self-esteem & 89 & 0,560 \\
Social impact & 89 & 0,225 & $0,000^{* *}$ \\
$\begin{array}{c}\text { Psychological } \\
\text { impact }\end{array}$ & 89 & 0,238 & $0,034^{*}$ \\
$\begin{array}{c}\text { Aesthetic } \\
\text { impact }\end{array}$ & 89 & 0,248 & $0,024^{*}$ \\
\hline
\end{tabular}

Based on table 4, it is known that the aspects of self-esteem, social impact, psychological impact and aesthetic impact have a positive value correlation coefficient where the higher the AC IOTN grade the higher the score of each aspect of the PIDAQ questionnaire. Based on the results of statistical tests there is a significant effect on the anterior teeth appearance based on Aesthetic Component of IOTN on the aspects of confidence, social impact, psychological impact, and aesthetic impact.

The results of this study show that the sample is not satisfied with his teeth and embarrassed to show his teeth when smile — teenagers more attention to aesthetics than adults [14]. 
Dissatisfaction with the appearance of teeth will make a person feel difficulties in managing his emotions, especially in adolescence [11]. According to Rosseau,adolescent stage is the peak of emotional development [15].

This study also shows that a sample who the appearance of teeth was in a high grade of AC IOTN,they feel a greater social impact compared with respondents who have a low-grade tooth appearance. Shaw, et al stated that the appearance of teeth can affect the perceptions of social characteristics such as friendliness, popularity, social class, and intelligence. According to Kerosuo, et al [16], malocclusion is often associated with unpleasant personality by others [17]. Malocclusion and unattractive tooth appearance can have a negative social impact (Badran, 2010). According to Piovesan et al [18] who studided the children in Brazil, dentofacial aesthetic plays an important role in social interaction. Children who have an aesthetic tooth appearance get an unpleasant response and get the nickname or mockery from their friends. Debora research (2014) found children's with malocclusion anterior teeth often inferiority, rarely smile and close their mouth when talking [19].

This psychological impact is related to one's self esteem. Self-esteem is one of the more specific components of self-concept, involving elements of evaluation or self-assessment including physical appearance [20], [21]. Individuals with low self-esteem tend to view themselves negatively and focus on their own weaknesses [21]. Malocclusion treatment will improve profile and increase confident [18].

In general, adolescents always pay attention to appearance and aesthetic. Dissatisfaction with the appearance of teeth is largely associated with very irregular tooth structure. In some people with severe malocclusions they are satisfied or do not pay much attention to the aesthetic of their teeth, but some are greatly disturbed by a slight irregularity of teeth [6]. De Olivera and Sheiham [22] suggest that $80 \%$ of orthodontic patients make aesthetic problems as reasons for orthodontic treatment rather than health problems and impaired oral function [23].

The results of this study were also found in Paula et al [8] studies on adolescents in Brazil where there was a significant relationship between malocclusions and the aesthetic impact aspect of the PIDAQ questionnaire. Debora et all [19] orthodontic treatment improves psychosocial adoslescent. Klages, et al [17] also found a significant relationship between AC IOTN grade and esthetic impact aspects. However, Sardenberg et al [24] did not find a significant effect between dental appearance based on dental aesthetic index and esthetic impact aspect. Based on the results of this study can be concluded that the appearance of anterior teeth based on Aesthetic Component of IOTN have an aesthetic effect on students of SMAN 10 Padang.

\section{Conclusion}

The most samples are in Grade 1 AE IOTN. There is a significant effect between the anterior teeth appearance based on Aesthetic Component from IOTN and the psychosocial state of adolescents.

\section{References}

[1] S. N. Anthony, K. Zimba, and B. Subramanian, "Impact of Malocclusions on the Oral Health-Related Quality of Life of Early Adolescents in Ndola, Zambia," Int. J. Dent., vol. 2018, pp. 1-8, Jun. 2018.

[2] W. R. Proffit, H. W. Fields, and D. M. Sarver, Contemporary Orthodontics. St. Louis: 
Mosby, 2007.

[3] T. M. A. Mahmood and F. A. Kareem, "Psychological impact of dental aesthetics for Kurdish young adults seeking orthodontic treatment," J. baghdad Coll. Dent., vol. 24, no. special issue 1, pp. 146-152, 2012.

[4] M. Khan and M. Fida, "Assessment of psychosocial impact of dental aesthetics," J. Coll. Physicians Surg. Pakistan, vol. 18, no. 9, p. 559, 2008.

[5] A. Dariyo, Psychology of adolescents. Bogor: Ghalia Indonesia, 2004.

[6] J. B. Nevin and R. Keim, "Social Psychology of Facial Appearance," in Biomechanics and Esthetic Strategies in Clinical Orthodontics, Elsevier, 2005, pp. 94-109.

[7] L. Mitchell, An Introduction of Orthodontics. New York: Oxford University Press, 1998.

[8] D. F. P. Jr, É. T. Silva, A. C. V. Campos, M. O. Nuñez, and C. R. Leles, "Effect of anterior teeth display during smiling on the self-perceived impacts of malocclusion in adolescents," Angle Orthod., vol. 81, no. 3, pp. 540-545, May 2011.

[9] P. H. Brook and W. C. Shaw, "The development of an index of orthodontic treatment priority," Eur. J. Orthod., vol. 11, no. 3, pp. 309-320, 1989.

[10] O. Hunt, "The Aesthetic Component of the Index of Orthodontic Treatment Need validated against lay opinion," Eur. J. Orthod., vol. 24, no. 1, pp. 53-59, Feb. 2002.

[11] E. S. A. Traebert and M. A. Peres, "Do malocclusions affect the individual's oral healthrelated quality of life?," Oral Health Prev. Dent., vol. 5, no. 1, 2007.

[12] C. Bellot-Arcís and J. M. Almerich-Silla, "Psychosocial impact of malocclusion in Spanish adolescents," Korean J. Orthod., vol. 43, no. 4, pp. 193-200, 2013.

[13] J. de Paula, N. C. M. Santos, É. T. da Silva, M. F. Nunes, and C. R. Leles, "Psychosocial Impact of Dental Esthetics on Quality of Life in Adolescents," Angle Orthod., vol. 79, no. 6, pp. 1188-1193, Nov. 2009.

[14] Z. Akarslan, B. Sadik, H. Erten, and E. Karabulut, "Dental esthetic satisfaction, received and desired dental treatments for improvement of esthetics," Indian J. Dent. Res., vol. 20, no. 2, p. 195, 2009.

[15] S. W. Sarwono, "Psikologi Ulayat," J. Psikol. Ulayat, vol. 1, no. 1, Dec. 2012.

[16] H. Kerosuo, H. Hausen, T. Laine, and W. C. Shaw, "The influence of incisal malocclusion on the social attractiveness of young adults in Finland," Eur. J. Orthod., vol. 17 , no. 6 , pp. 505-512, 1995.

[17] U. Klages, N. Claus, H. Wehrbein, and A. Zentner, "Development of a questionnaire for assessment of the psychosocial impact of dental aesthetics in young adults," Eur. J. Orthod., vol. 28, no. 2, pp. 103-111, Oct. 2005.

[18] L. P. Queiroz et al., "Chronic daily headache in Brazil: a nationwide population-based study," Cephalalgia, vol. 28, no. 12, pp. 1264-1269, 2008.

[19] D. L. S. Scheffel, F. Jeremias, C. M. B. Fragelli, L. A. M. dos Santos-Pinto, J. Hebling, and O. B. de Oliveira, "Esthetic dental anomalies as motive for bullying in schoolchildren," Eur. J. Dent., vol. 8, no. 1, pp. 124-128, Jan. 2014.

[20] K. A. Loscocco, J. Robinson, R. H. Hall, and J. K. Allen, "Gender and small business success: An inquiry into women's relative disadvantage,” Soc. forces, vol. 70, no. 1, pp. 65-85, 1991.

[21] A. Aditomo and S. Retnowati, "Perfeksionisme, harga diri, dan kecenderungan depresi pada remaja akhir," J. Psikol., vol. 31, no. 1, pp. 1-14, 2004.

[22] C. M. De Oliveira and A. Sheiham, "The relationship between normative orthodontic treatment need and oral health-related quality of life," Community Dent. Oral Epidemiol., vol. 31, no. 6, pp. 426-436, 2003.

[23] J. Rusanen, S. Lahti, M. Tolvanen, and P. Pirttiniemi, "Quality of life in patients with 
severe malocclusion before treatment," Eur. J. Orthod., vol. 32, no. 1, pp. 43-48, Sep. 2009.

[24] F. Sardenberg, A. C. Oliveira, S. M. Paiva, S. M. Auad, and M. P. Vale, "Validity and reliability of the Brazilian version of the psychosocial impact of dental aesthetics questionnaire," Eur. J. Orthod., vol. 33, no. 3, pp. 270-275, Aug. 2010. 